\title{
Subacromial decompression surgery for adults with shoulder pain: a systematic review with meta- analysis
}

\author{
Tuomas Lähdeoja (D) ,',2 Teemu Karjalainen, ${ }^{1,3}$ Jarkko Jokihaara, 1,4 Paul Salamh, ${ }^{5}$ \\ Lauri Kavaja, ${ }^{6,7}$ Arnav Agarwal, ${ }^{8}$ Marinus Winters (D) , ${ }^{9}$ Rachelle Buchbinder (1) , \\ Gordon Guyatt, ${ }^{10}$ Per Olav Vandvik, ${ }^{11,12}$ Clare LArdern (1) ${ }^{13,14}$
}

- Additional material is published online only. To view please visit the journal online (http://dx.doi.org/10.1136/ bjsports-2018-100486).

For numbered affiliations see end of article.

\section{Correspondence to} Dr Tuomas Lähdeoja, Department of Orthopaedics and Traumatology, Helsinki University Hospital, PL 00029 HUS, Helsinki, Finland; tuomas.lahdeoja@hus.fi

Accepted 18 December 2018 Published Online First 15 January 2019
Check for updates

(C) Author(s) (or their employer(s)) 2020. No commercial re-use. See rights and permissions. Published by BMJ.

To cite: Lähdeoja T, Karjalainen T, Jokihaara J, et al. Br J Sports Med 2020;54:665-673.

\section{ABSTRACT}

Objective To determine the benefits and harms of subacromial decompression surgery in adult patients with subacromial pain syndrome lasting for more than 3 months.

Design Systematic review with meta-analysis.

Main outcome measures Pain, physical function and health-related quality of life.

Data sources Systematic searches for benefits and harms were conducted to 23 July 2018 in MEDLINE, Embase, PubMed, Cochrane Central Register of Controlled Trials, Cochrane Database of Systematic Reviews, Cumulative Index to Nursing and Allied Health Literature, Physiotherapy Evidence Database, ClinicalTrials.gov, WHO International Clinical Trials Registry Platform, Database of Abstracts of Reviews of Effects, and Health Technology Assessment.

\section{Eligibility criteria for selecting}

studies Randomised controlled trials comparing subacromial decompression surgery for subacromial pain syndrome with any other treatment(s). For harms, we included prospective cohort studies.

Review methods Two reviewers independently determined eligibility, extracted the data and assessed the risk of bias of eligible studies. Thirty patients seeking primary or outpatient care for subacromial pain syndrome and a parallel guideline committee (BMJ Rapid Recommendations) provided input regarding systematic review design and interpretation.

Results There was high certainty evidence of no additional benefit of subacromial decompression surgery over placebo surgery in reducing pain at 1 year following surgery (mean difference [MD] -0.26 , $95 \% \mathrm{Cl}-0.84$ to 0.33 , minimally important difference [MID] 1.5) or improving physical function at 1-2 years (MD 2.8, 95\% Cl -1.4 to 6.9, MID 8.3). There was moderate certainty evidence for no additional benefit of subacromial decompression surgery on healthrelated quality of life at 1 year (MD -0.03 points, $95 \% \mathrm{Cl}-0.11$ to 0.06 , MID 0.07). There was moderate certainty evidence for six serious harms per 1000 (95\% Cl 5 to 7) patients undergoing subacromial decompression.

Conclusion Subacromial decompression surgery provided no important benefit compared with placebo surgery or exercise therapy, and probably carries a small risk of serious harms.

Systematic reviewregistration number CRD42018086862.

\section{What is already known}

- Subacromial decompression surgery is a common procedure.

- Unblinded trials at high risk of bias have failed to demonstrate the benefit of subacromial decompression surgery compared with exercise therapy for subacromial pain syndrome.

- Two recently published placebo surgerycontrolled trials provide low risk of bias evidence regarding the efficacy of surgery.

What are the new findings

- Compared with placebo surgery, subacromial decompression surgery does not provide additional benefits with respect to pain, function or quality of life in adults with subacromial pain syndrome, and probably causes rare serious harms (moderate to high certainty evidence).

- Compared with exercise therapy, subacromial decompression surgery probably provides a small but likely unimportant improvement in pain (moderate certainty) and may not improve function in adults with subacromial pain syndrome (low certainty).

- Policymakers, guideline developers, clinicians and patients should reconsider the role of subacromial decompression surgery in practice.

\section{INTRODUCTION}

Every year, up to 1 in every 50 adults in the UK seek care for new-onset shoulder pain. ${ }^{12}$ Subacromial pain syndrome (SAPS) - also known as shoulder impingement or rotator cuff disease-is the most common diagnosis. ${ }^{3}$ Based on rotator cuff lesions found in cadaver shoulders, surgeons hypothesised that SAPS arises due to impingement of the rotator cuff tendons between the head of the humerus and the undersurface of the acromion process. ${ }^{45}$

This mechanistic hypothesis has driven the use of subacromial decompression surgery-removal of the subacromial bursa and some bone from the anteroinferior surface of the acromion to prevent impingement on the rotator cuff tendons. Guidelines currently recommend surgical treatment of SAPS unresponsive to first-line management 
Box 1 Linked articles in this BMJ Rapid

Recommendations cluster

- Vandvik PO, Lähdeoja T, Ardern C, et al. Subacromial decompression surgery for adults with shoulder pain: a clinical practice guideline (accepted BMJ).

- Hao Q, Devji T, Zeraatkar D, et al. Minimal important differences in shoulder condition outcomes: a systematic review to inform a $B M J$ Rapid Recommendation (in review, BMJ Open).

- Lähdeoja T, Karjalainen T, Jokihaara J, et al. Subacromial decompression surgery for adults with shoulder pain: a systematic review with meta-analysis.

An updated Cochrane systematic review (Karjalainen T et al, Cochrane Database of Systematic Reviews 2019, Issue 1. Art. No: CD005619. DOI: 10.1002/14651858.CD005619.pub3) was performed in parallel on subacromial decompression surgery for rotator cuff disease.

(typically a combination of exercise therapy, corticosteroid injections and activity modification). ${ }^{67}$

Responding to biological rationale, the ease of arthroscopic surgery and clinical practice guidelines, surgeons-depending on where they practice-conduct between 19 and 132 subacromial decompression surgeries per 100000 persons each year; rates have increased at least fivefold over the past two decades. ${ }^{8-11}$ In the UK, surgeons conduct over 21000 procedures every year. ${ }^{8}$

This systematic review addressing the benefits and harms of subacromial decompression surgery compared with other interventions in adult patients with SAPS lasting for more than 3 months informs the 13th BMJ Rapid Recommendations-a series of trustworthy clinical practice recommendations published in response to potentially practice-changing evidence (box 1). Two recent trials that compared subacromial decompression surgery with placebo surgery triggered this systematic review. ${ }^{12} 13$ These studies have the potential to guide clinical practice by providing an unbiased estimate of the efficacy of subacromial decompression surgery above and beyond any placebo effects. ${ }^{1415}$

\section{METHODS}

We followed the Preferred Reporting Items for Systematic Reviews and Meta-Analyses statement ${ }^{16}$ when conducting and reporting this prospectively registered systematic review (PROSPERO trial registration number: CRD42018086862).

We conducted this systematic review in collaboration with a parallel update of a Cochrane Review-both review teams agreed on the methods, results and overlapping authorship, and shared work on key review steps, to align with the needs of the BMJ Rapid Recommendations panel.

\section{BMJ Rapid Recommendations and patient involvement}

In accordance with the BMJ Rapid Recommendations process, ${ }^{17}$ a guideline panel provided critical input and guidance during the review process, which included identifying populations, subgroups and outcomes of interest. The OMERACT (Outcome Measures in Rheumatology) draft core domain set for clinical trials of shoulder disorders ${ }^{18}$ formed the starting point for consideration of outcomes of interest.

The guideline panel included content experts, front-line clinicians, methodologists and four patients with lived experience of SAPS . Patients received personal training and support to contribute throughout the guideline development process. They were full members of the guideline panel, contributed to the selection and prioritisation of outcomes, and provided critical feedback to the BMJ Rapid Recommendations manuscript.

The guideline panel also requested a linked systematic review to identify the most credible estimates of minimally important differences (MIDs) for pain, function and quality of life (Hao $\mathrm{Q}$ et al., in submission). We used the most credible MID estimates to inform judgements regarding estimates of effect in our systematic review, and to determine the importance of observed differences in effects, reflecting patients' values and preferences.

\section{Patient involvement in this systematic review}

In addition to the input from patients in the guideline panel, we involved a second group of patients to help prioritise the outcomes for this systematic review. We invited 33 patients seeking care for SAPS in an orthopaedic outpatient clinic (Helsinki University Hospital) and a primary care unit (Occupational Health Helsinki) to answer a questionnaire addressing their shoulder condition. We queried, with open questions, what was the most bothersome symptom, and asked respondents to name the three most important activities affected by their shoulder problem.

Thirty patients answered our questionnaire. Pain was the most bothersome symptom for 26 patients (86\%). The most commonly affected activities were disturbed sleep, difficulties elevating the arm and participation in sports.

\section{Eligibility criteria}

We included randomised controlled trials comparing subacromial decompression surgery for SAPS with any other treatment(s) in adults. Because SAPS is a clinical diagnosis, we did not set strict diagnostic criteria. Instead, we accepted studies' own criteria for SAPS diagnoses with no requirement for imaging. We excluded trials in which any enrolled patient had a symptom duration of less than 3 months. Subacromial decompression surgery was defined as open or arthroscopic bursectomy and/or acromioplasty. As the anticipated effects and outcomes of relevance are similar following open and arthroscopic acromioplasty, ${ }^{19} 20$ we combined data from these two surgical approaches.

We excluded trials with mixed diagnoses across participants, including calcific tendinitis, full-thickness rotator cuff tears and secondary shoulder pain (post-traumatic, laxity, thrower's shoulder and so on, diagnosed by imaging or at surgery) unless it was possible to extract data from patients with SAPS separately.

For harms, we anticipated trial data would not represent the best body of evidence due to few events and incomplete reporting. In our protocol we stated that we would include studies regardless of design. However, we realised that wellperformed observational studies designed to detect harms, including consecutive samples of patients undergoing surgery, outside the context of strictly controlled trials, provide much higher certainty evidence of rare harms than designs at higher risk of bias. Therefore, we included only prospective cohort studies on harms after shoulder arthroscopy for a variety of diagnoses including SAPS from registries designed to evaluate harms. We did not specify a minimum symptom duration and there were no exclusion criteria. Among the identified studies we selected studies that provided estimates of harms with the highest certainty. In this assessment we emphasised the risk of bias and issues related to indirectness (eg, type of patients, surgery and time frame for recording harms). 


\section{Literature search}

For trials regarding efficacy, we searched MEDLINE, Embase, PubMed, Cochrane Central Register of Controlled Trials (CENTRAL), Cumulative Index to Nursing and Allied Health Literature (CINAHL), Physiotherapy Evidence Database (PEDro), ClinicalTrials.gov and WHO International Clinical Trials Registry Platform. We used the Cochrane Highly Sensitive Search Strategy for identifying randomised trials in MEDLINEsensitivity-maximising and precision-maximising version (2008 revision) in MEDLINE and PubMed-and adapted for other sources where needed.

For harms, we searched MEDLINE, Embase, PubMed, CENTRAL, Cochrane Database of Systematic Reviews, Database of Abstracts of Reviews of Effects, Health Technology Assessment, CINAHL and PEDro.

All searches were performed from database inception to 23 July 2018 (search strategies for all databases are in online supplementary appendix), excluding animal studies and publication types unlikely to contain relevant information (news, comments, letters to the editor and editorials) but without other search limits.

\section{Study selection}

Two independent reviewers evaluated eligibility and extracted data using records imported to the Covidence systematic review software (Veritas Health Innovation, Melbourne, Australia; www. covidence.org). When necessary, we obtained full-text articles to determine eligibility for inclusion, including English-language translations. Disagreements were resolved by discussion.

\section{Outcomes}

The guideline panel identified outcomes of importance to patients; we used outcomes from the trials that most closely corresponded to those chosen by the patients (table 1). Because it was the most bothersome symptom for $86 \%$ of the patients who completed our survey, we considered pain as the most important outcome in this systematic review.

We defined serious harms as death, bleeding (uncontrolled or requiring transfusion), cardiac arrest requiring cardiopulmonary

Table 1 Patient-important outcomes identified by the guideline panel aligned to the most corresponding outcome set available in the included trials and studies

Panel-identified outcomes

Outcomes chosen from included trials and

Pain

Pain (visual analogue scale and numeric rating scale various scales)

Physical function

Combined outcomes of physical function, physical capacity and pain items (Constant Score and its modifications, Shoulder Disability Questionnaire, Neer Score). We refer to these as 'function' outcomes for simplicity.

\begin{tabular}{ll}
$\begin{array}{l}\text { Global perceived effect } \\
\text { Quality of life }\end{array}$ & $\begin{array}{l}\text { Global perceived effect. The outcome was derived } \\
\text { by subtracting the patients who reported 'worse' } \\
\text { or 'much worse' from the number of patients } \\
\text { reporting 'much better' or 'no shoulder problems at } \\
\text { all'/'healed completely' at the relevant time points. }\end{array}$ \\
\hline Participation & $\begin{array}{l}\text { Health-related quality of life (EQ-5D-3L and 15D). } \\
\text { Return to leisure activities/sport. } \\
\text { Working status (working yes/no). }\end{array}$ \\
\hline $\begin{array}{l}\text { Development of full-thickness } \\
\text { rotator cuff tears }\end{array}$ & $\begin{array}{l}\text { Prevalence of full-thickness rotator cuff tears at } \\
\text { follow-up. }\end{array}$ \\
\hline Harms & Serious harms. \\
\hline
\end{tabular}

resuscitation, myocardial infarction, cerebrovascular accident, acute renal failure, unplanned intubation, requiring ventilator for $>48$ hours, deep infection (surgical site or organ/space), sepsis, septic shock, pneumonia, wound dehiscence, pulmonary embolism, deep vein thrombosis or peripheral nerve injury.

\section{Data extraction}

Two independent reviewers extracted outcome data for all available follow-up assessments. If authors did not report relevant numeric outcome data in the text, we contacted the authors or, when available, extracted the data from figures and graphs. We also extracted the following data: trial characteristics, patient demographic variables, diagnosis, treatment and data about trial methodology. Online supplementary appendix table 1 presents a full list of extracted data items.

We used a priori-defined decision rules for data extraction:

1. When triallists reported final values and change from baseline values for the same outcome, we extracted the final values.

2. When triallists reported unadjusted and adjusted values for the same outcome, we extracted the unadjusted values.

3. When triallists reported data based on the intention-to-treat (ITT) sample and another sample (eg, per-protocol, astreated), we extracted ITT-analysed data.

\section{Risk of bias assessment}

Two independent reviewers assessed the risk of bias in included trials using the Cochrane Risk of Bias Tool ${ }^{21}$ and assessed all the publications including protocols. We categorised outcomes as patient-reported or clinician-assessed, and classified outcome measures with mixed patient-reported and clinician-assessed items as patient-reported. When a trial had multiple follow-up time points, we assessed these individually, but the overall risk of bias was judged prioritising follow-up of 6 months to 1 year.

We used the Quality In Prognosis Studies tool ${ }^{22}$ to assess the risk of bias in observational studies contributing data to the estimate of serious harms.

\section{Data management}

When trials used different outcome measures to evaluate the same construct, we chose the most common outcome measure as the index and transformed mean differences (MD) and SD of other outcome measures to the index instrument, and pooled the data using MD as the summary estimate. ${ }^{2324}$ When large variations in SDs led to problematic weights in the meta-analysis, we pooled standardised mean differences (SMD). In this case, the SMDs were back-transformed to the scale of the index outcome measure. If SDs or $95 \%$ CIs were unavailable, we imputed the SD using the most representative study.

For trials not reporting the index instrument, we followed a prespecified outcome hierarchy when deciding which data would be pooled (online supplementary appendix table 2). For Farfaras et al, $^{25}$ we combined ${ }^{15}$ the open and arthroscopic subacromial decompression surgery arms in all analyses.

\section{Data synthesis and analysis}

In the meta-analysis, we synthesised continuous outcome data using MDs and SDs. We estimated the absolute values in the control group by applying the median of the means, and in the intervention group by summing the pooled MDs and SDs to the medians of the means. For dichotomous outcome data, we used relative risk for synthesis. We calculated the absolute estimates of effect by applying relative risk estimates from the meta-analysis to a baseline risk, for which we used the pooled 
mean of the control groups of the included trials. We used RevMan V.5.3 (Copenhagen: The Nordic Cochrane Centre, The Cochrane Collaboration, 2014) for the meta-analyses, with the generic inverse-variance random-effects model for continuous outcomes, and Mantel-Haenszel method and random effects for dichotomous outcomes. We assessed statistical heterogeneity with the $\chi^{2}$ and $\mathrm{I}^{2}$ statistics.

We conducted meta-analyses, guided by considerations of bias. For the primary comparison, we pooled data from comparisons at low risk of bias. For the secondary comparison, we pooled data from comparisons irrespective of risk of bias.

We assessed outcomes at 3 months, 6 months, 1 year, 2 years (for which we pooled data up to 3 years if no 2 -year data were available), 5 years (we prioritised time points closest to 5 years) and $>10$ years following randomisation.

For harms, we calculated incidence proportions using a generalised linear model, using a binomial distribution and an identity link function.

\section{Sensitivity analyses}

We planned a sensitivity analysis for pain at 1 year to assess the impact of attrition bias due to missing data, ${ }^{26}$ but due to low risk of attrition bias this was not conducted. We also planned to assess small study bias by inspecting the distribution of funnel plots, ${ }^{27}$ but there were too few trials.

\section{Subgroup analyses}

We planned a number of subgroup analyses, based on shoulderrelated classifications, but because there were fewer than 10 trials ${ }^{15}$ we were unable to carry these out. Planned sensitivity and subgroup analyses are detailed in the PROSPERO registration.

\section{Certainty of evidence}

For all outcomes, we assessed the certainty of evidence of benefits of surgery compared with other treatments and harms of surgery using the Grading of Recommendations Assessment, Development and Evaluation (GRADE) approach. We appraised the potential limitations due to risk of bias, inconsistency, imprecision, indirectness and publication bias. We created summary of findings tables using MAGICapp (www.magicapp.org) to provide evidence summaries with relative and absolute effects across all outcomes and associated certainty.

\section{RESULTS}

\section{Benefits}

The search yielded 842 records. Of these, we considered the full texts of 15 trials for inclusion. After full-text review, 9 trials (18 publications including 2 trial protocols) fulfilled the eligibility criteria (see flow chart in online supplementary appendix figure 1). ${ }^{12132528-42}$

\section{Study characteristics}

The 9 eligible trials included 1014 patients. The mean age at baseline ranged from 43 to 59 years (table 2 and online supplementary appendix table 3 ). Two trials ${ }^{12}{ }^{13}$ compared subacromial decompression surgery with placebo surgery. Both trials also included a non-surgical arm. Five trials 2530333541 compared

\begin{tabular}{|c|c|c|c|c|c|c|}
\hline Trial & Intervention(s) and control & Age, years* & Proportion of women & Symptom duration, years & Baseline paint & Baseline function $\neq^{*}$ \\
\hline \multirow[t]{3}{*}{ Paavola et a $/^{13}$} & ASAD $(n=59)$ & $50.5(7.3)$ & $71 \%(42 / 59)$ & $1.5(1.2)$ & $7.12(2.36)$ & $32.2(28.2$ to 36.2$)$ \\
\hline & $\mathrm{DA}(\mathrm{n}=63)$ & $50.8(7.6)$ & $73 \%(46 / 63)$ & $1.5(1.6)$ & $7.23(2.17)$ & 31.7 (28.2 to 35.2$)$ \\
\hline & ET (71) & $50.4(6.6)$ & $66 \%(47 / 71)$ & $1.9(1.9)$ & $7.24(2.08)$ & $35.2(31.4$ to 39.0$)$ \\
\hline \multirow[t]{3}{*}{ Beard et al ${ }^{12}$} & $\operatorname{ASAD}(n=106)$ & $52.9(10.3)$ & $51 \%(54 / 106)$ & - & $6.0(1.9)$ & $39.4(13.9)$ \\
\hline & $\mathrm{DA}(\mathrm{n}=103)$ & $53.7(10.5)$ & $50 \%(52 / 103)$ & - & $5.8(2.0)$ & $43.1(15.5)$ \\
\hline & WaS $(n=104)$ & $53.2(10.2)$ & $50 \%(52 / 104)$ & - & $6.6(1.7)$ & $38.3(14.2)$ \\
\hline \multirow[t]{3}{*}{ Farfaras et $a^{25}$} & $\operatorname{ASAD}(n=29)$ & - & - & - & - & $56(11.3)$ \\
\hline & OSAD $(n=24)$ & - & - & - & - & $48(15.7)$ \\
\hline & ET $(n=34)$ & - & - & - & - & $56(13.1)$ \\
\hline \multirow[t]{2}{*}{ Ketola et $a^{\beta 5}$} & $\operatorname{ASAD}(n=70)$ & 46.4 & $56 \%(41 / 70)$ & $2.5(0.25-17)$ & 6.4 & 22.0 \\
\hline & ET $(n=70)$ & 47.8 & $67 \%(47 / 70)$ & $2.6(0.25-20)$ & 6.5 & 17.5 \\
\hline \multirow[t]{2}{*}{ Henkus et $a l^{34}$} & $\operatorname{ASAD}(n=30)$ & 50.0 & $47 \%(14 / 30)$ & - & 7.9 & 57 \\
\hline & BT $(n=26)$ & 43.0 & $65 \%(17 / 26)$ & - & 6.8 & 56 \\
\hline \multirow[t]{2}{*}{ Taverna et $a l^{42}$} & ASAD $(n=30)$ & $52.0(7)$ & $57 \%(17 / 30)$ & - & $8.2(0.8)$ & $54(4)$ \\
\hline & MT $(n=30)$ & $53.0(7)$ & $70 \%(21 / 30)$ & - & $8.4(0.9)$ & $51(4)$ \\
\hline \multirow[t]{2}{*}{ Haahr et al ${ }^{33}$} & $\operatorname{ASAD}(n=41)$ & 44.3 & $71 \%(29 / 41)$ & - & 6.56 (5.78 to 7.33$)$ & 33.7 (29.2 to 38.2$)$ \\
\hline & ET $(n=43)$ & 44.5 & $67 \%(29 / 43)$ & - & 7.22 (6.56 to 7.78$)$ & 34.7 (30.4 to 39.0$)$ \\
\hline \multirow[t]{2}{*}{ Peters and Kohn ${ }^{41}$} & $\operatorname{SAD}(n=32)$ & 56 & $44 \%(14 / 32)$ & - & - & 54 \\
\hline & $\mathrm{CT}(\mathrm{n}=40)$ & 59 & $30 \%(12 / 40)$ & - & - & 59 \\
\hline \multirow[t]{3}{*}{ Brox et a $\left.\right|^{30}$} & ASAD $(n=45)$ & 48.0 & $36 \%(16 / 45)$ & - & $7.25(1.9)$ & $63.4(10.8)$ \\
\hline & ET $(n=50)$ & 47.0 & $56 \%(28 / 50)$ & - & $6.89(2.3)$ & $66.3(8.8)$ \\
\hline & Laser $(n=30)$ & 48.0 & $50 \%(15 / 30)$ & - & $6.96(2.5)$ & $64.7(10.6)$ \\
\hline
\end{tabular}

\footnotetext{
Values presented as mean (SD) for age, mean (SD, minimum-maximum) for symptom duration, mean (SD, 95\% CI) for baseline pain and mean (SD, 95\% CI) for baseline function. ${ }^{*}$ Medians reported by Peters and Kohn. ${ }^{41}$

†Measures were transformed to a $0-10$ scale, with a higher score indicating less pain.

¥Measures were transformed to a 0-100 scale, with a higher score indicating superior function.

ASAD, arthroscopic subacromial decompression surgery; BT, bursectomy; CT, conservative therapy including ET; DA, diagnostic arthroscopy; ET, exercise therapy; MT, microtenotomy; OSAD, open subacromial decompression surgery; SAD, subacromial decompression surgery; WaS, wait and see.
} 
subacromial decompression surgery with exercise therapy; one had a placebo laser arm with no active treatment. ${ }^{30}$

One trial ${ }^{34}$ compared acromioplasty plus bursectomy with bursectomy alone. One trial ${ }^{42}$ compared acromioplasty with bursectomy plus radiofrequency-device microtenotomy. We excluded both trials from the meta-analysis because they compared different approaches to subacromial decompression surgery.

\section{Risk of bias assessment}

For the comparisons of subacromial decompression surgery versus placebo surgery, the risk of bias was low for all outcomes (online supplementary appendix table 4). Due to detection bias (all studies), selection bias, ${ }^{25}$ attrition bias ${ }^{25}{ }^{35}$ and selective reporting, ${ }^{33}{ }^{41}$ for the comparisons of subacromial decompression surgery versus non-surgical treatment, the risk of bias was high for all outcomes except rotator cuff tears (online supplementary appendix table 4).

\section{Primary comparisons}

Two trials ${ }^{12}{ }^{13}$ were at low risk of bias and sufficiently clinically and methodologically homogeneous to allow pooling for the comparison of subacromial decompression surgery plus postoperative rehabilitation versus placebo surgery plus postoperative rehabilitation. Table 3 and online supplementary appendix table 5 present the GRADE summary of findings for outcomes for this comparison.

For pain (VAS, 0-10, lower better, MID=1.5 units), we found high certainty evidence of no benefit of surgery at 6 months ( 2 trials, 299 participants: MD $0.07,95 \% \mathrm{CI}-0.51$ to $0.64, \mathrm{I}^{2}=0 \%, \mathrm{p}=0.82$ ) or at 1 year ( 2 trials, 284 participants: $\mathrm{MD}-0.26,95 \% \mathrm{CI}-0.84$ to $0.33, \mathrm{I}^{2}=0 \%, \mathrm{p}=0.39$ ) (figure 1 ,

Table 3 GRADE Summary of findings for the comparison of subacromial decompression surgery with placebo surgery

\begin{tabular}{|c|c|c|c|c|c|}
\hline $\begin{array}{l}\text { Outcome, time } \\
\text { frame }\end{array}$ & Measurement instruments and relative effects & \multicolumn{2}{|l|}{ Absolute effect estimates } & $\begin{array}{l}\text { Certainty in effect } \\
\text { estimates (quality } \\
\text { of evidence) }\end{array}$ & Plain text summary \\
\hline Pain, 6 months & $\begin{array}{l}\text { Measured by VAS and NRS scaled to } 0-10 \text {. } \\
\text { Scale: } 0-10 \text {, lower better. } \\
\text { MID: } 1.5 \text { units. } \\
\text { Based on data from } 299 \text { patients in } 2 \text { studies. }\end{array}$ & $\begin{array}{l}3.9 \\
\text { Difference: MD } 0.07 \text { higher } \\
\text { (95\% Cl } 0.51 \text { lower to } 0.64 \text { higher). }\end{array}$ & 4.0 & High. & $\begin{array}{l}\text { Surgery has little or no effect } \\
\text { on pain at } 6 \text { months. }\end{array}$ \\
\hline Pain, 1 year & $\begin{array}{l}\text { Measured by VAS and NRS scaled to } 0-10 . \\
\text { Scale: } 0-10 \text {, lower better. } \\
\text { MID: } 1.5 \text { units. } \\
\text { Based on data from } 284 \text { patients in } 2 \text { studies. }\end{array}$ & $\begin{array}{l}2.9 \\
\text { Difference: MD } 0.26 \text { lower } \\
\text { ( } 95 \% \text { Cl } 0.84 \text { lower to } 0.33 \text { higher). }\end{array}$ & 2.6 & High. & $\begin{array}{l}\text { Surgery has little or no effect } \\
\text { on pain at } 1 \text { year. }\end{array}$ \\
\hline Function, 6 months & $\begin{array}{l}\text { Measured by Constant Score. } \\
\text { Scale: } 0-100 \text {, higher better. } \\
\text { MID: } 8.3 \text { points. } \\
\text { Based on data from } 286 \text { patients in } 2 \text { studies. }\end{array}$ & $\begin{array}{l}61 \\
\text { Difference: MD } 3.72 \text { lower } \\
\text { (95\% CI } 8.72 \text { lower to } 1.28 \text { higher). }\end{array}$ & 57 & High. & $\begin{array}{l}\text { Surgery has little or no effect } \\
\text { on function at } 6 \text { months. }\end{array}$ \\
\hline Function, $1-2$ years & $\begin{array}{l}\text { Measured by Constant Score. } \\
\text { Scale: } 0-100 \text {, higher better. } \\
\text { MID: } 8.3 \text { points. } \\
\text { Based on data from } 274 \text { patients in } 2 \text { studies. }\end{array}$ & $\begin{array}{l}69 \\
\text { Difference: MD } 2.76 \text { higher } \\
\text { ( } 95 \% \text { CI } 1.36 \text { lower to } 6.87 \text { higher). }\end{array}$ & 72 & High. & $\begin{array}{l}\text { Surgery has little or no effect } \\
\text { on function at } 1-2 \text { years. }\end{array}$ \\
\hline $\begin{array}{l}\text { Global perceived } \\
\text { effect, } 1 \text { year }\end{array}$ & $\begin{array}{l}\text { Relative risk: } 1.1 \text { ( } 95 \% \text { Cl } 0.94 \text { to } 1.3 \text { ). } \\
\text { Based on data from } 290 \text { patients in } 2 \text { studies. }\end{array}$ & $\begin{array}{l}635 \text { per } 1000 \\
\text { Difference: } 64 \text { more per } 1000 \\
\text { (95\% Cl } 38 \text { fewer to } 190 \text { more). }\end{array}$ & 699 per 1000 & $\begin{array}{l}\text { Moderate, } \\
\text { due to serious } \\
\text { imprecision*. }\end{array}$ & $\begin{array}{l}\text { Surgery probably has little } \\
\text { or no global perceived effect } \\
\text { at } 1 \text { year. }\end{array}$ \\
\hline $\begin{array}{l}\text { Quality of life, } \\
6 \text { months }\end{array}$ & $\begin{array}{l}\text { Measured by EQ- } 5 \text { D. } \\
\text { Scale: }-0.59-1 \text {, higher better. } \\
\text { MID: } 0.07 \text { units. } \\
\text { Based on data from } 292 \text { patients in } 2 \text { studies. }\end{array}$ & $\begin{array}{l}0.67 \\
\text { Difference: MD } 0.01 \text { lower } \\
\text { ( } 95 \% \text { Cl } 0.08 \text { lower to } 0.05 \text { higher). }\end{array}$ & 0.66 & High. & $\begin{array}{l}\text { Surgery has little or no effect } \\
\text { on quality of life at } 6 \text { months. }\end{array}$ \\
\hline $\begin{array}{l}\text { Quality of life, } \\
1 \text { year }\end{array}$ & $\begin{array}{l}\text { Measured by EQ-5D. } \\
\text { Scale: }-0.59-1 \text {, higher better. } \\
\text { MID: } 0.07 \text { units. } \\
\text { Based on data from } 285 \text { patients in } 2 \text { studies. }\end{array}$ & $\begin{array}{l}0.73 \\
\text { Difference: MD } 0.03 \text { lower } \\
\text { (95\% Cl } 0.11 \text { lower to } 0.06 \text { higher). }\end{array}$ & 0.70 & High. & $\begin{array}{l}\text { Surgery has little or no effect } \\
\text { on quality of life at } 1 \text { year. }\end{array}$ \\
\hline
\end{tabular}

*Imprecision: serious, wide Cls.

tSerious harms were death, bleeding (uncontrolled or requiring transfusion), cardiac arrest requiring cardiopulmonary resuscitation, myocardial infarction, cerebrovascular accident, acute renal failure, unplanned intubation, ventilator $>48$ hours, deep infection (surgical site or organ/space), sepsis, septic shock, wound dehiscence, pulmonary embolism, deep vein thrombosis and peripheral nerve injury.

łIndirectness: serious. Differences between the intervention of interest and those studied; observational studies included other arthroscopic shoulder surgeries in addition to subacromial decompressions only.

§Imprecision: very serious. Low number of patients/events, wide Cls.

MID, minimally important difference; NRS, numeric rating scale; RCT, randomised controlled trial; VAS, visual analogue scale. 
a

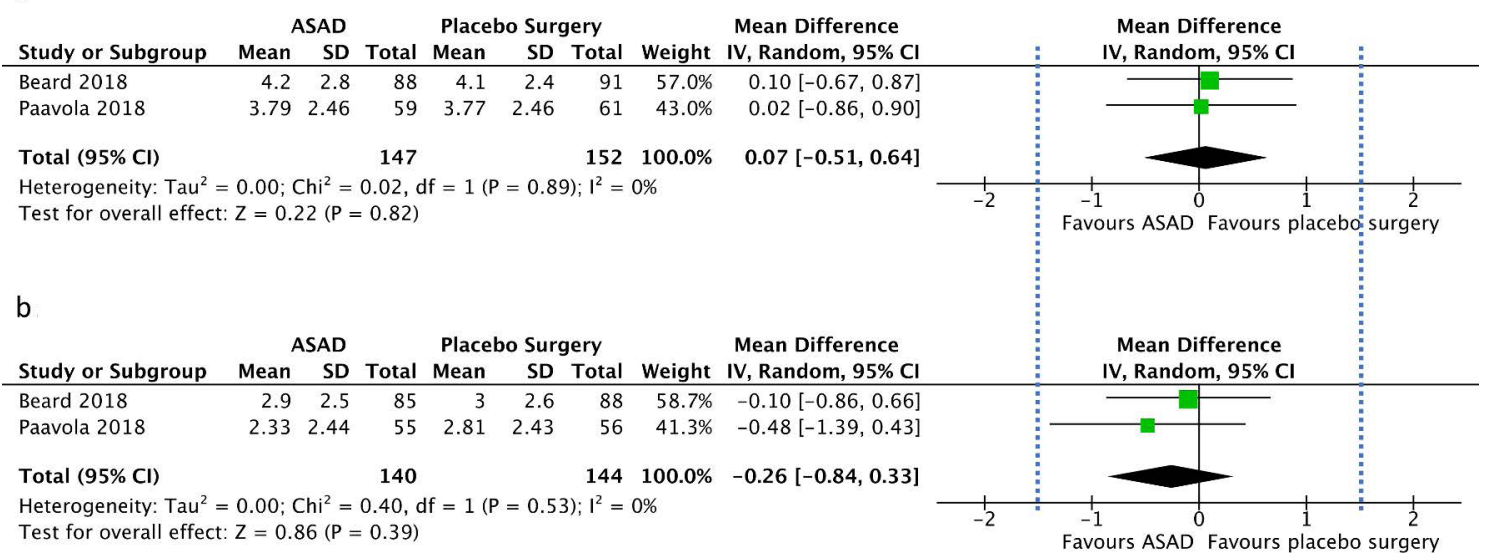

Figure 1 Forest plots of pain at (A) 6 months and (B) 1 year. Dashed vertical line denotes minimally important difference (1.5 units, lower better). ASAD, arthroscopic subacromial decompression surgery,IV, inverse-variance.

figure 2). One trial reported pain at 3 months and 2 years (online supplementary appendix table 5).

For function (Constant Score, 0-100, higher better, MID =8.3 points), we found high certainty evidence of no benefit of surgery at 6 months ( 2 trials, 286 participants: $\mathrm{MD}-3.7,95 \% \mathrm{CI}-8.7$ to $1.3, \mathrm{I}^{2}=30 \%, \mathrm{p}=0.08$ ) or at $1-2$ years ( 2 trials, 274 participants: $\mathrm{MD} 2.8,95 \% \mathrm{CI}-1.4$ to $6.9, \mathrm{I}^{2}=0 \%, \mathrm{p}=0.19$ ) (figure 3 , figure 4).

For global perceived effect, we found moderate certainty evidence of no benefit of surgery at 6 months ( 2 trials, 293 participants: relative risk (RR) $1.04,95 \%$ CI 0.81 to 1.34 ) or at 1 year (2 trials, 290 participants: RR $1.10,95 \%$ CI 0.94 to 1.30 ) (online supplementary appendix figure 2).
For health-related quality of life (EQ-5D, -0.59 to 1 , MID 0.07 units), we found high certainty evidence of no benefit of surgery at 6 months ( 2 trials, 292 participants: SMD -0.05 , $95 \% \mathrm{CI}-0.27$ to 0.18 , which back-transformed to -0.01 points, $95 \% \mathrm{CI}-0.08$ to 0.05 in EQ-5D) or at 1 year ( 2 trials, 285 participants: SMD $-0.09,95 \% \mathrm{CI}-0.39$ to 0.21 , which back-transformed to -0.03 points, $95 \% \mathrm{CI}-0.11$ to 0.06 in EQ-5D) (online supplementary appendix figure 3).

One trial reported return to work and return to sport/leisure activities, providing low certainty evidence of no benefit of surgery in participation in work or sport/leisure activities at all time points (online supplementary appendix table 5).

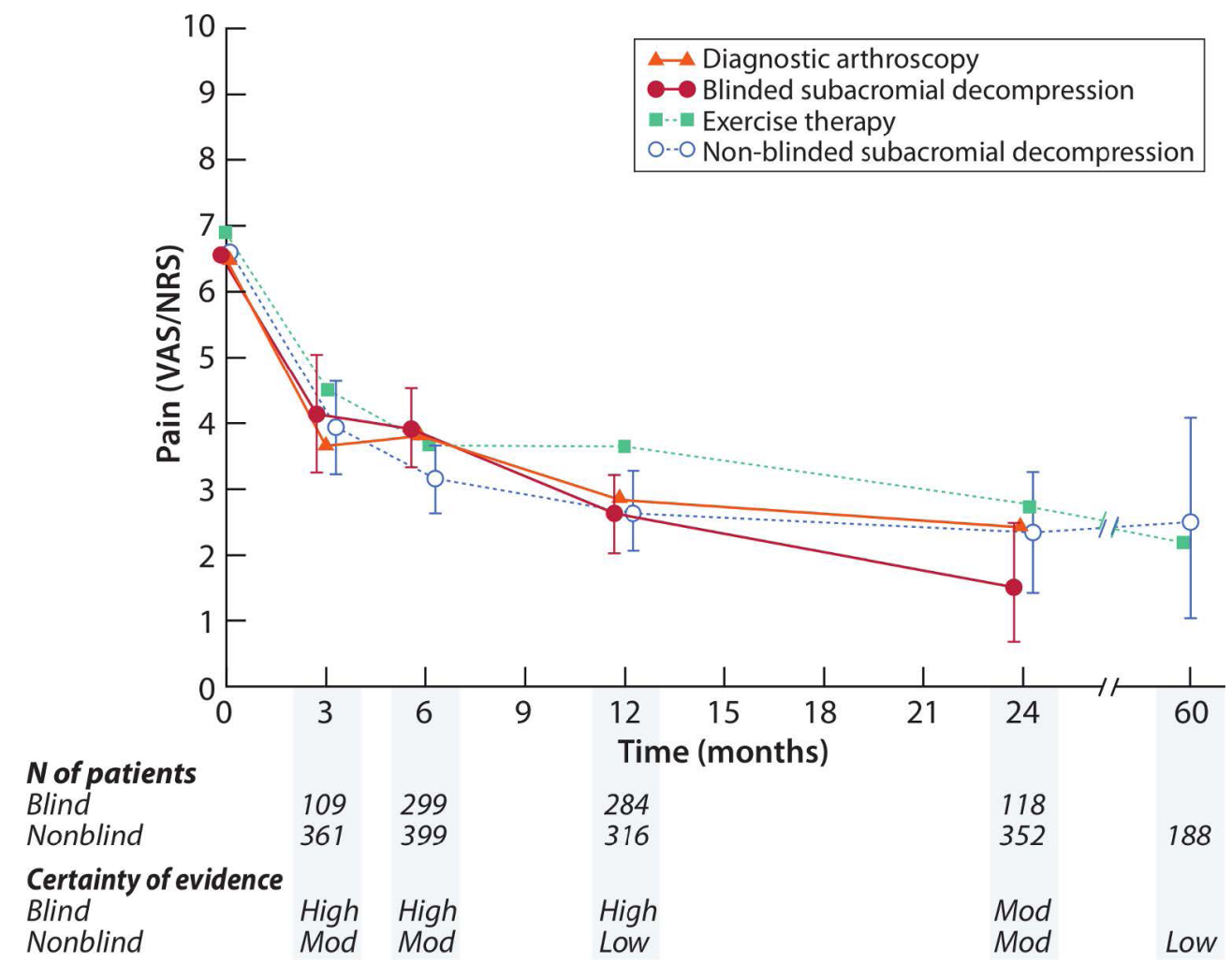

Figure 2 Change in pain over time for all available time points. Control group (diagnostic arthroscopy and exercise therapy) values are medians of the mean pain values in the trials. Intervention group values are control groups values + mean differences with $95 \%$ Cls from the meta-analysis (VAS, visual analogue scale, MID=1.5 units). MID, minimally important difference; Mod, moderate; NRS, numeric rating scale. 
a

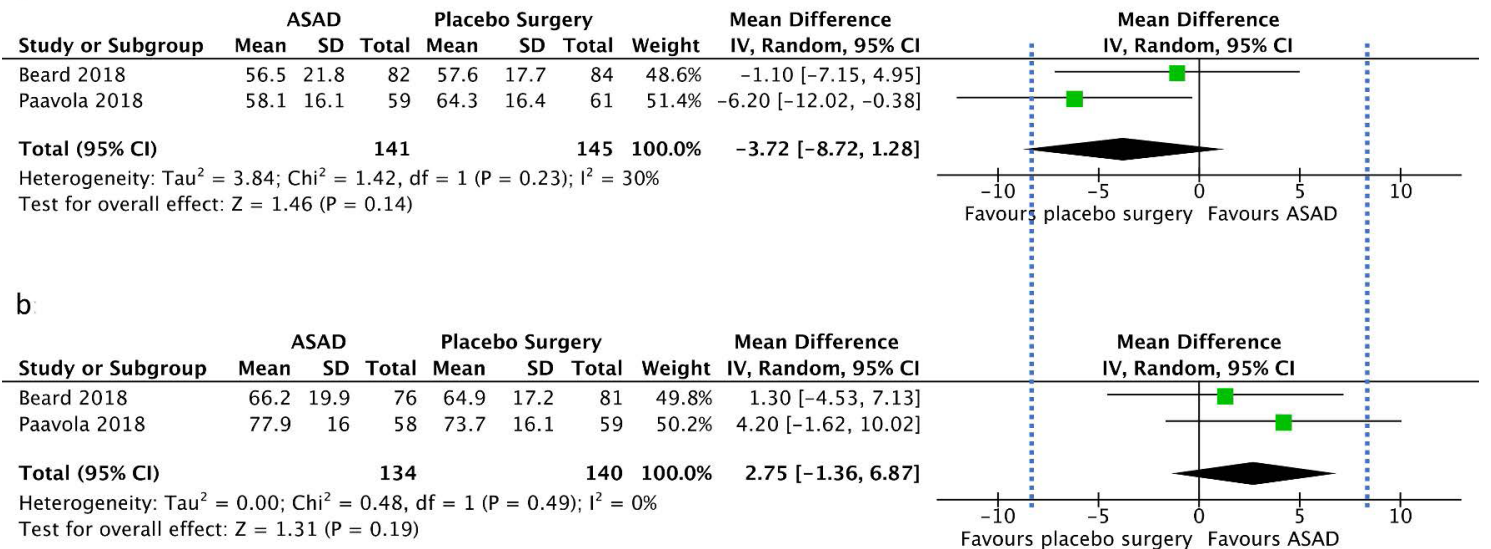

Figure 3 Forest plots of function at (A) 6 months and (B) 1-2 years (Beard et al, ${ }^{12} 1$ year; Paavola et al, ${ }_{1}^{13} 2$ years). Dashed vertical line denotes minimally important difference ( 8.3 points, higher better). ASAD, arthroscopic subacromial decompression surgery; IV, inverse-variance.

Studies included in the primary comparison provided no data regarding the prevalence of full-thickness rotator cuff tears at follow-up.

\section{Secondary comparisons}

Comparisons in six trials 253033354041 were at high risk of bias and sufficiently clinically and methodologically homogeneous to allow pooling for the comparison of subacromial decompression surgery plus postoperative rehabilitation versus exercise therapy alone. Online supplementary appendix table 6 presents the GRADE summary of findings for this comparison.

For pain (VAS, 0-10, MID 1.5 units), we found moderate certainty evidence of no patient-important benefit of surgery at 3 months (4 trials, 361 participants: MD -0.55 , 95\% CI -1.24 to 0.14 ) and 6 months (4 trials, 399 participants: MD -0.56 ,
$95 \% \mathrm{CI}-1.09$ to -0.02 ), and at 2 years ( 3 trials, 352 participants: $\mathrm{MD}-0.44,95 \% \mathrm{CI}-1.37$ to 0.48 ) (table 3 , online supplementary appendix figure 4$)$ and 5 years (2 trials, 188 participants: $\mathrm{MD} 0.36,95 \% \mathrm{CI}-1.17$ to 1.89 ). At 1 year (3 trials, 316 participants: $\mathrm{MD}-1.01,95 \% \mathrm{CI}-1.60$ to -0.42 ) we found low certainty evidence of a small benefit, which is likely unimportant for patients (figure 2, online supplementary appendix figure 4). One trial reported pain at 10 years.

For function (transformed to Constant Score, 0-100), we found low certainty evidence of no patient-important benefit at 3 (3 trials, 257 participants: $\mathrm{MD} 6.1,95 \% \mathrm{CI}-5.6$ to 17.8 ) and 6 (4 trials, 398 participants: MD 3.7, 95\% CI -2.3 to 9.6 ) months, and at 1 (3 trials, 259 participants: MD 3.2, 95\% CI -8.1 to 14.6 ), 2 (5 trials, 467 participants: $\mathrm{MD} 4.9,95 \% \mathrm{CI}$ 0.8 to 9.1 ) and 5 (2 trials, 157 participants: $\mathrm{MD} 7.6,95 \% \mathrm{CI}$

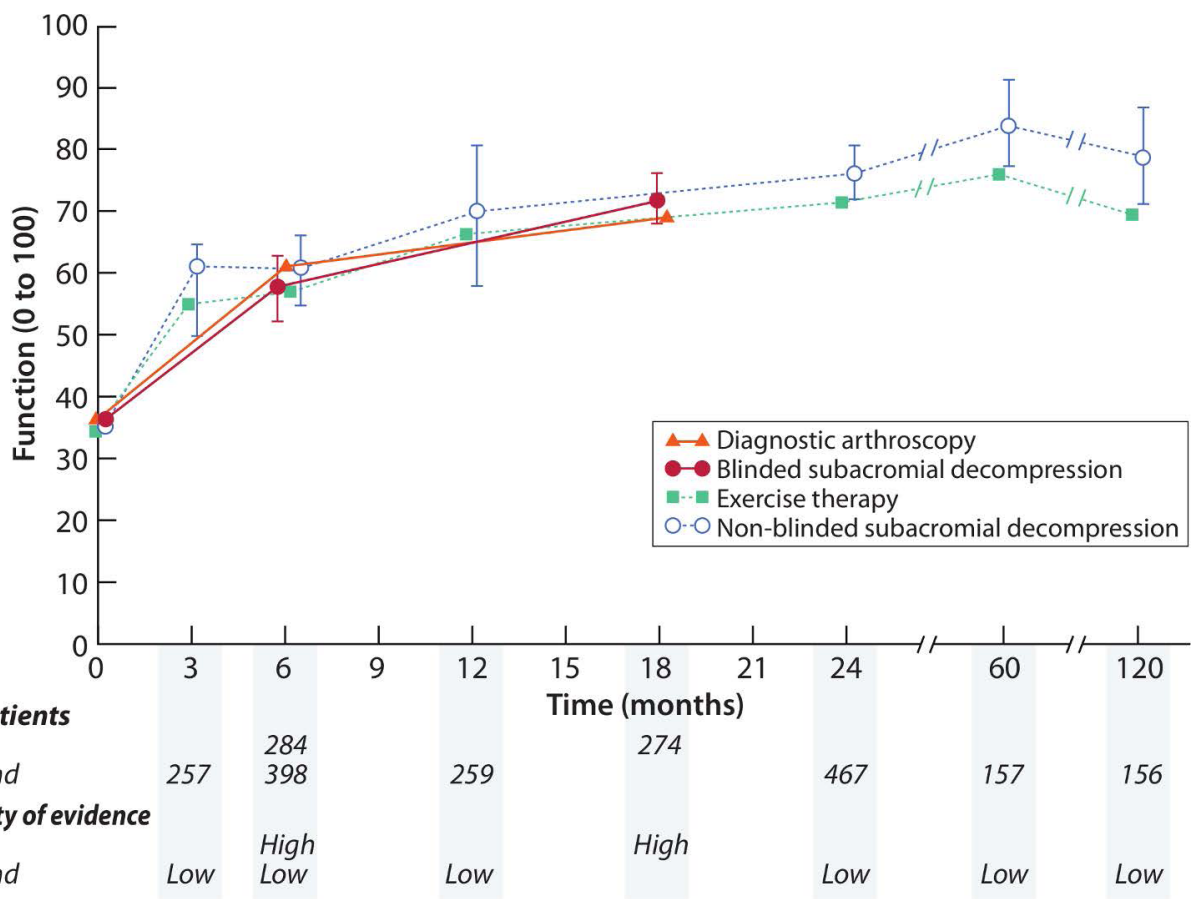

Figure 4 Change in function over time for all available time points. Control group (diagnostic arthroscopy and exercise therapy) values are medians of the mean function values in the trials. Intervention group values are control groups values + mean differences with $95 \% \mathrm{Cls}$ from the metaanalysis. Constant Score MID=8.3 points. Data pooled from 1-year and 2-year time points are presented at 18 months. MID, minimally important difference. 
0.2 to 15.1 ) years. At 10 years, we found low certainty evidence of a mean patient-important benefit ( 2 trials, 156 participants: MD 9.5, 95\% CI 1.9 to 17.2) (figure 4, online supplementary appendix figure 5). The CI included values that were lower than the MID.

We found moderate certainty evidence of no benefit in the number of patients working at 6 months ( 2 trials, 187 participants: RR $1.05,95 \%$ CI 0.81 to 1.36 ) and 2 years ( 2 trials, 183 participants: RR $0.87,95 \%$ CI 0.70 to 1.07$)$. Only single-study data were available for working status at 3 months, 1 year and 10 years. One study reported return to sports/leisure activities, with no difference between groups (online supplementary appendix table 6, online supplementary appendix figure 6).

We found low certainty evidence of no benefit of surgery in the incidence of full-thickness supraspinatus tendon tears (diagnosed with $\mathrm{MRI}^{36}$ ) at 5 years ( 1 trial, 90 participants: RR 1.00, $95 \%$ CI 0.40 to 2.52 ). ${ }^{31}$ (online supplementary appendix table $6)$.

\section{Harms}

Both placebo-controlled trials reported harms, ${ }^{15} 16$ while two of the trials with non-surgical comparisons reported that there were no harms ${ }^{33} 38$ and three did not mention harms. ${ }^{253341}$ Overall the included trials provide low certainty evidence regarding harms due to small sample size and incomplete reporting. The two placebo-controlled trials reported five participants experiencing frozen shoulder in the subacromial decompression group and three in the placebo surgery group (table 3 ). Four participants experienced frozen shoulder in the non-surgical groups. One patient who received placebo surgery experienced temporary swelling related to a brachial plexus block.

The search for studies addressing harms yielded 2363 records, of which 140 were assessed in full text for eligibility. We excluded 138 of these publications (online supplementary appendix figure 1). The data of the four remaining studies came from the same large prospective registry designed to record harms. ${ }^{43}$ Of the four studies, one assessed harms in patients over 65 years and was excluded due to unrepresentative patient population. Of the remaining three, one was excluded as it enrolled a subset of patients in the two other studies, leaving two studies that were included. The studies addressed 30 -day harms after a variety of shoulder arthroscopic procedures including subacromial decompression surgery. We found no eligible studies reporting data separately for subacromial decompression surgeries.

We based our estimates of harms on two studies from the same registry, reporting harms over two slightly overlapping time periods. ${ }^{44} 45$ The studies included $15015^{44}$ and 10 $225^{45}$ patients, both at low risk of bias (online supplementary appendix table 7). The incidence of serious harms following mixed shoulder arthroscopic procedures during 2006-2011 was $0.5 \%(0.4 \%-0.7 \%)^{45}$ and during 2011-2013 was 0.6\% (0.5\%$0.7 \%) .{ }^{44}$ Online supplementary appendix table 8 presents the details of harms. Longer duration of surgery ( $>1.5$ hours) was associated with harms (OR in one study $1.80,95 \%$ CI 1.29 to $2.50^{43}$; adjusted OR in the other $1.93,95 \%$ CI 1.21 to $3.07^{45}$ ). One report noted that harms from 'major' or 'repair' procedures were similar to harms for 'minor' or 'non-repair' procedures (adjusted OR 0.77, 95\% CI 0.48 to 1.22 ). ${ }^{45}$ Because these studies reported results from a variety of arthroscopic shoulder procedures, many of which take longer to perform, we rated down the evidence to moderate certainty.

\section{DISCUSSION}

Because surgery often has a powerful, placebo effect lasting at least a year, ${ }^{46}$ we prioritised comparisons between subacromial decompression surgery and placebo surgery in patients with SAPS. Two recent trials at low risk of bias provided high certainty evidence for no important benefit of subacromial decompression surgery on reduction of pain, or improvement of physical function and health-related quality of life over placebo surgery at 6 months to 1 year. Trial data at 2 years' follow-up and results from unblinded comparisons in six trials comparing subacromial decompression surgery with exercise therapy provided consistent estimates of no patient-important benefit, with low to moderate certainty evidence. The randomised trials did not report any serious harms. For potential harms from subacromial decompression surgery, we found moderate certainty evidence from two well-performed observational studies from the same registry reporting that 5-6 in 1000 patients would experience a serious harm.

\section{Strengths and limitations of the systematic review}

Our systematic review includes evidence from placebo surgerycontrolled trials, is based on a comprehensive search for observational studies on harms and directly involved patients. Our results extend previous research by including high certainty evidence from placebo-controlled trials and by considering, through establishing best estimates of MIDs (H Qea, in review), results in light of what patients would consider important. Our findings are consistent with previous systematic reviews ${ }^{2048}$ that found very limited evidence of any benefit of subacromial decompression surgery versus exercise therapy for treating SAPS. We made an a priori decision to extend our analysis of potential harms to include observational data because RCTs will be underpowered for serious rare harms.

We invited patients to guide us in prioritising outcomes for our systematic review, an important step in ensuring that research aiming to guide shared decision-making addresses the issues most important to patients. ${ }^{49}$

\section{Inferences and implications}

On average, patients with SAPS reported reduced pain, and improved physical function and quality of life following both surgical and non-surgical treatment. However, at up to 5 years, irrespective of treatment, patients continued to report pain of an average of $1.5-3$ on a scale of $0-10$ points on a visual analogue scale. Clinicians working in primary care who are treating patients with SAPS should be aware that some patients experience prolonged symptoms and consider care strategies to support coping. ${ }^{50-52}$

A placebo control helps answer the research question 'is there a benefit of subacromial decompression surgery?' because it minimises the risk of detection and performance biases. Both sources of bias contribute to overestimation of treatment effects by up to $20 \%{ }^{53}$ The largely consistent findings of the unblinded studies leave little doubt of the inference that subacromial decompression surgery provides no important benefit to patients.

The current evidence provides no support for subacromial decompression surgery as an intervention providing important benefit for patients with SAPS. High-quality evidence indicates that surgery versus placebo surgery confers no important benefit on pain and function-the outcomes most important to patients. Considering the body of evidence, further headto-head comparisons of subacromial decompression surgery compared with placebo surgery or non-surgical management 
with the same population are unlikely to change the results. Policymakers, funders and clinicians should consider these results in their funding and clinical decisions regarding the management of patients with shoulder pain.

\section{Unanswered questions and future research}

Our review was designed to assess the benefits and harms of subacromial decompression surgery for managing SAPS. To date, no trial has demonstrated benefit of surgery for any clinical subgroup. In the future, subgroup claims should be supported by data from well-conducted trials at low risk of bias and the use of established criteria for credibility of subgroup effects, ${ }^{54}$ ideally enhanced by individual participant data meta-analysis. ${ }^{55}$ For harms we welcome well-performed observational studies that specifically report harms after subacromial decompression surgery separately from harms following other types of shoulder surgery.

Although the finding of no important benefit of surgery is robust, the root cause of subacromial pain and the underlying pathological process remain uncertain, as does the possible best treatment-if such exists-for SAPS. Network meta-analysis might provide information on this question and provide hypotheses to be tested in future methodologically sound trials. Future triallists investigating any treatment for SAPS should adopt a common set of outcomes, ${ }^{18}$ and the outcome measures should be standardised. ${ }^{56}$

\section{CONCLUSION}

Subacromial decompression surgery for SAPS provided no important benefit compared with placebo surgery or exercise therapy, and is probably associated with a risk of serious harms.

\author{
Author affiliations \\ ${ }^{1}$ Finnish Centre for Evidence-Based Orthopedics (FICEBO), University of Helsinki, \\ Helsinki, Finland \\ ${ }^{2}$ Department of Orthopaedics and Traumatology, HUS Helsinki University Hospital, \\ Helsinki, Finland \\ ${ }^{3}$ Monash Department of Clinical Epidemiology, Cabrini Institute; and Department \\ of Epidemiology and Preventive Medicine, School of Public Health and Preventive \\ Medicine, Monash University, Malvern, Victoria, Australia \\ ${ }^{4}$ Department of Hand Surgery, Tampere University Hospital, Tampere, Finland \\ ${ }^{5}$ College of Health Sciences, University of Indianapolis, Indianapolis, Indiana, USA \\ ${ }^{6}$ Medical Faculty, University of Helsinki, Helsinki, Finland \\ ${ }^{7}$ Department of Surgery, South Karelia Central Hospital, Lappeenranta, Finland \\ ${ }^{8}$ Department of Medicine, University of Toronto, Toronto, Ontario, Canada \\ ${ }^{9}$ Research Unit for General Practice in Aalborg, Department of Clinical Medicine, \\ Aalborg University, Aalborg, Denmark \\ ${ }^{10}$ Department of Health Research Methods, Evidence, and Impact, McMaster \\ University, Hamilton, Ontario, Canada \\ ${ }^{11}$ Department of Medicine, Lovisenberg Diaconal Hospital, Oslo, Norway \\ ${ }^{12}$ Faculty of Medicine, Institute of Health and Society, University of Oslo, Oslo, \\ Norway \\ ${ }^{13}$ Division of Physiotherapy, Linköping University, Linköping, Sweden \\ ${ }^{14} \mathrm{~S} c h o o l$ of Allied Health, La Trobe University, Melbourne, Victoria, Australia
}

Acknowledgements We thank Jaana Isojärvi for assistance with the literature search. We thank the members of the Rapid Recommendations panel for feedback on outcome and subgroup selection, and for manuscript feedback, especially Reed Siemieniuk, Rudolf Poolman and Michel van den Bekerom. Our thanks to the 30 patients who gave us feedback on the key outcomes for this systematic review, and to Jussi Mustonen for help with the patient survey in Occupational Health Helsinki. Thank you to Carlo Ramponi, Renato Andrade, Mario Bizzini, Alan McCall, Thomas Ibounig, Ömer Acar, Alexandre Santos, Magdalena Kobierska, Martin Lehecka and Otso Lähdeoja for help with article translations. Finally, we thank Professor Teppo Järvinen for suggesting that the time might be right for a systematic review on this topic.

Contributors TL, CLA and MW conceived of and designed the study. JJ, TK, POV, RB and GG provided critical feedback on the design. TL, CLA and JJ designed and coordinated the direct patient involvement. Screening and study selection:
TL and JJ for benefits, and PS, LK, AA and TL for harms. Data extraction: JJ and TK for benefits, and PS, LK, AA, TL and CLA for harms. TL and TK performed the data analyses, and CLA and POV took part in the interpretation of the analyses for benefits. CLA analysed the data for harms. TL, CLA and POV performed risk of bias and certainty of evidence assessments. TL and CLA wrote the manuscript. MW, TK, $J J, R B, P O V$ and GG critically revised the manuscript. All authors approved the final version of the manuscript. TL, TK and RB coordinated the parallel reviews. TL is the guarantor.

Funding The authors have not declared a specific grant for this research from any funding agency in the public, commercial or not-for-profit sectors.

Competing interests None declared.

Patient consent for publication Obtained.

Ethics approval Patient involvement in this systematic review and meta-analysis was approved by the Helsinki and Uusimaa Hospital District Ethics Committee (HUS/1736/2018, 6 June 2018). Informed consent was obtained from all patients.

Provenance and peer review Not commissioned; internally peer reviewed.

Data sharing statement Additional data are available in the publication of the BMJ Rapid Recommendations in MAGICapp and the parallel Cochrane Review. Extracted data are available in full from the authors upon request.

\section{ORCID iDs}

Tuomas Lähdeoja http://orcid.org/0000-0002-9053-8888

Marinus Winters http://orcid.org/0000-0001-5742-7441

Rachelle Buchbinder http://orcid.org/0000-0002-0597-0933

Clare L Ardern http://orcid.org/0000-0001-8102-3631

\section{REFERENCES}

1 Urwin M, Symmons D, Allison T, et al. Estimating the burden of musculoskeletal disorders in the community: the comparative prevalence of symptoms at different anatomical sites, and the relation to social deprivation. Ann Rheum Dis 1998;57:649-55

2 Bot SD, van der Waal JM, Terwee CB, et al. Incidence and prevalence of complaints of the neck and upper extremity in general practice. Ann Rheum Dis 2005;64:118-23.

3 Mitchell C, Adebajo A, Hay E, et al. Shoulder pain: diagnosis and management in primary care. BMJ 2005;331:1124-8.

4 Codman EA, Akerson IB. The pathology associated with rupture of the supraspinatus tendon. Ann Surg 1931;93:348-59.

5 Neer CS. Anterior acromioplasty for the chronic impingement syndrome in the shoulder: a preliminary report. J Bone Joint Surg Am 1972;54:41-50.

6 Kulkarni R, Gibson J, Brownson P, et al. Subacromial shoulder pain. Shoulder Elbow 2015:7:135-43.

7 Statement from the Shoulder and Elbow Society of Australia (an AOA subspecialty society) to the Medical Observe. 2017.

8 Judge A, Murphy RJ, Maxwell R, et al. Temporal trends and geographical variation in the use of subacromial decompression and rotator cuff repair of the shoulder in England. Bone Joint J 2014;96-B:70-4.

9 Paloneva J, Lepola V, Karppinen J, et al. Declining incidence of acromioplasty in Finland. Acta Orthop 2015;86:220-4.

10 Vitale MA, Arons RR, Hurwitz S, et al. The rising incidence of acromioplasty. J Bone Joint Surg Am 2010;92:1842-50.

11 Yu E, Cil A, Harmsen WS, et al. Arthroscopy and the dramatic increase in frequency of anterior acromioplasty from 1980 to 2005: an epidemiologic study. Arthroscopy 2010;26(9 Suppl):S142-7.

12 Beard DJ, Rees JL, Cook JA, et al. Arthroscopic subacromial decompression for subacromial shoulder pain (CSAW): a multicentre, pragmatic, parallel group, placebocontrolled, three-group, randomised surgical trial. Lancet 2018;391:329-38.

13 Paavola M, Malmivaara A, Taimela S, et al. Subacromial decompression versus diagnostic arthroscopy for shoulder impingement: randomised, placebo surgery controlled clinical trial. BMJ 2018;362:k2860.

14 Fletcher F. Clinical Epidemiology. The essentials. 5th edn. Philadelphia, Pennsylvania, USA: Lippincott Williams and Wilkins, 2012.

15 GSe H. Cochrane handbook for systematic reviews of interventions version 5.1.0: The Cochrane Collaboration, 2011.

16 Moher D, Liberati A, Tetzlaff J, et al. Preferred reporting items for systematic reviews and meta-analyses: the PRISMA statement. PLoS Med 2009;6:e1000097.

17 Siemieniuk RA, Agoritsas T, Macdonald H, et al. Introduction to BMJ Rapid Recommendations. BMJ 2016;354:i5191.

18 Buchbinder $\mathrm{R}$, Page MJ, Huang $\mathrm{H}$, et al. A preliminary core domain set for clinical trials of shoulder disorders: a report from the OMERACT 2016 shoulder core outcome set special interest group. J Rheumatol 2017:44:1880-3.

19 Barfield LC, Kuhn JE. Arthroscopic versus open acromioplasty: a systematic review. Clin Orthop Relat Res 2007;455:64-71.

20 Coghlan JA, Buchbinder R, Green S, et al. Surgery for rotator cuff disease. Cochrane Database Syst Rev 2008;1:CD005619. 
21 The Cochrane Collaboration. Chapter 8: Assessing risk of bias in included studies. In: Higgins JPT AD, Sterne JAC, eds. Cochrane Handbook for Systematic Reviews of Interventions Version 5.1.0: The Cochrane Collaboration, 2011.

22 Hayden JA, van der Windt DA, Cartwright JL, et al. Assessing bias in studies of prognostic factors. Ann Intern Med 2013;158:280-6.

23 Guyatt GH, Thorlund K, Oxman AD, et al. GRADE guidelines: 13. Preparing summary of findings tables and evidence profiles-continuous outcomes. J Clin Epidemiol 2013:66:173-83.

24 Thorlund K, Walter SD, Johnston BC, et al. Pooling health-related quality of life outcomes in meta-analysis-a tutorial and review of methods for enhancing interpretability. Res Synth Methods 2011;2:188-203.

25 Farfaras S, Sernert N, Hallström E, et al. Comparison of open acromioplasty, arthroscopic acromioplasty and physiotherapy in patients with subacromial impingement syndrome: a prospective randomised study. Knee Surg Sports Traumatol Arthrosc 2016:24:2181-91.

26 Ebrahim S, Akl EA, Mustafa RA, et al. Addressing continuous data for participants excluded from trial analysis: a guide for systematic reviewers. J Clin Epidemiol 2013;66:1014-21.

27 Sterne JA, Sutton AJ, loannidis JP, et al. Recommendations for examining and interpreting funnel plot asymmetry in meta-analyses of randomised controlled trials. BMJ 2011;343:d4002.

28 Beard D, Rees J, Rombach I, et al. The CSAW Study (Can Shoulder Arthroscopy Work?) - a placebo-controlled surgical intervention trial assessing the clinical and cost effectiveness of arthroscopic subacromial decompression for shoulder pain: study protocol for a randomised controlled trial. Trials 2015;16:210.

29 Brox Jl, Gjengedal E, Uppheim G, et al. Arthroscopic surgery versus supervised exercises in patients with rotator cuff disease (stage II impingement syndrome): a prospective, randomized, controlled study in 125 patients with a 2 1/2-year follow-up J Shoulder Elbow Surg 1999;8:102-11.

30 Brox Jl, Staff PH, Ljunggren AE, et al. Arthroscopic surgery compared with supervised exercises in patients with rotator cuff disease (stage II impingement syndrome). BMJ 1993;307:899-903.

31 Farfaras S, Sernert N, Rostgard Christensen L, et al. Subacromial decompression yields a better clinical outcome than therapy alone: a prospective randomized study of patients with a minimum 10-year follow-up. Am J Sports Med 2018;46:1397-407.

32 Haahr JP, Andersen JH. Exercises may be as efficient as subacromial decompression in patients with subacromial stage II impingement: 4-8-years' follow-up in a prospective, randomized study. Scand J Rheumatol 2006;35:224-8.

33 Haahr JP, Østergaard S, Dalsgaard J, et al. Exercises versus arthroscopic decompression in patients with subacromial impingement: a randomised, controlled study in 90 cases with a one year follow up. Ann Rheum Dis 2005;64:760-4.

34 Henkus HE, de Witte PB, Nelissen RG, et al. Bursectomy compared with acromioplasty in the management of subacromial impingement syndrome: a prospective randomised study. J Bone Joint Surg Br 2009;91:504-10.

35 Ketola S, Lehtinen J, Arnala I, et al. Does arthroscopic acromioplasty provide any additional value in the treatment of shoulder impingement syndrome?: a two-year randomised controlled trial. J Bone Joint Surg Br 2009;91:1326-34.

36 Ketola S, Lehtinen J, Elo P, et al. No difference in long-term development of rotator cuff rupture and muscle volumes in impingement patients with or without decompression. Acta Orthop 2016;87:351-5.

37 Ketola S, Lehtinen J, Rousi T, et al. No evidence of long-term benefits of arthroscopicacromioplasty in the treatment of shoulder impingement syndrome: Fiveyear results of a randomised controlled trial. Bone Joint Res 2013;2:132-9.
38 Ketola S, Lehtinen JT, Arnala I. Arthroscopic decompression not recommended in the treatment of rotator cuff tendinopathy: a final review of a randomised controlled trial at a minimum follow-up of ten years. Bone Joint J 2017;99B:799-805.

39 Kolk A, Thomassen BJW, Hund $\mathrm{H}$, et al. Does acromioplasty result in favorable clinical and radiologic outcomes in the management of chronic subacromial pain syndrome? A double-blinded randomized clinical trial with 9 to 14 years' follow-up. J Shoulder Elbow Surg 2017;26:1407-15.

40 Paavola M, Malmivaara A, Taimela S, et al. Finnish Subacromial Impingement Arthroscopy Controlled Trial (FIMPACT): a protocol for a randomised trial comparing arthroscopic subacromial decompression and diagnostic arthroscopy (placebo control), with an exercise therapy control, in the treatment of shoulder impingement syndrome. BMJ Open 2017;7:e014087.

41 Peters G, Kohn D. [Mid-term clinical results after surgical versus conservative treatment of subacromial impingement syndrome]. Unfallchirurg 1997;100:623-9.

42 Taverna E, Battistella F, Sansone V, et al. Radiofrequency-based plasma microtenotomy compared with arthroscopic subacromial decompression yields equivalent outcomes for rotator cuff tendinosis. Arthroscopy 2007;23:1042-51.

43 American College of Surgeons. American College of Surgeons National Surgical Quality Improvement Program database. https://www.facs.org/quality-programs/acsnsqip

44 Hill JR, McKnight B, Pannell WC, et al. Risk factors for 30-day readmission following shoulder arthroscopy. Arthroscopy 2017;33:55-61.

45 Shields $E$, Thirukumaran C, Thorsness $R$, et al. An analysis of adult patient risk factors and complications within 30 days after arthroscopic shoulder surgery. Arthroscopy 2015:31:807-15.

46 Wartolowska K, Judge A, Hopewell S, et al. Use of placebo controls in the evaluation of surgery: systematic review. BMJ 2014;348:g3253.

47 Wartolowska KA, Feakins BG, Collins GS, et al. The magnitude and temporal changes of response in the placebo arm of surgical randomized controlled trials: a systematic review and meta-analysis. Trials 2016;17:589.

48 Saltychev M, Äärimaa V, Virolainen P, et al. Conservative treatment or surgery for shoulder impingement: systematic review and meta-analysis. Disabil Rehabil 2015;37:1-8.

49 Richards T, Schroter S, Price A, et al. Better together: patient partnership in medical journals. BMJ 2018;362:k3798.

50 Brox Jl. Regional musculoskeletal conditions: shoulder pain. Best Pract Res Clin Rheumatol 2003; 17:33-56.

51 Lewis J, O'Sullivan P. Is it time to reframe how we care for people with non-traumatic musculoskeletal pain? Br J Sports Med 2018;52:1543-4.

52 Waddell G. 1987 Volvo award in clinical sciences. A new clinical model for the treatment of low-back pain. Spine 1987;12:632-44.

53 Savovic J, Turner RM, Mawdsley D, et al. Association between risk-of-bias assessments and results of randomized trials in cochrane reviews: the ROBES meta-epidemiologic study. Am J Epidemiol 2018;187:1113-22.

54 Sun $X$, Briel M, Walter SD, et al. Is a subgroup effect believable? Updating criteria to evaluate the credibility of subgroup analyses. BMJ 2010;340:C117.

55 Burke DL, Ensor J, Riley RD. Meta-analysis using individual participant data: one-stage and two-stage approaches, and why they may differ. Stat Med 2017:36:855-75

56 Mokkink LB, Prinsen CA, Bouter LM, et al. The COnsensus-based Standards for the selection of health Measurement INstruments (COSMIN) and how to select an outcome measurement instrument. Braz J Phys Ther 2016;20:105-13. 